\title{
OPPOSING OFFSPRING SEX RATIO VARIATIONS WITH INCREASING AGE AND WEIGHT IN MOUFLON MOTHERS (Ovis musimon)
}

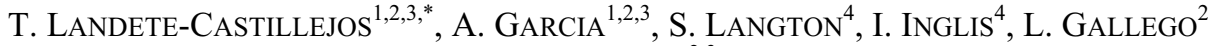 \\ and J. GARDE ${ }^{2,3}$ \\ ${ }^{1}$ Sección de Recursos Cinegéticos, IDR, ${ }^{2}$ Departamento de Ciencia y Tecnología Agro- \\ forestal, ETSIA and ${ }^{3}$ Instituto de Investigación en Recursos Cinegéticos (CSIC-UCLM- \\ JCCLM), Sección Albacete, Universidad de Castilla-La Mancha, 02071 Albacete, Spain; \\ ${ }^{4}$ MAFF Central Science Laboratory, Sand Hutton, York, UK
}

(Received July 12, 2000; accepted February 8, 2001)

\begin{abstract}
There are two main theories explaining offspring sex biases in polygynous mammals. Trivers and Willard (1973) argue that mothers with greater reproductive resources should invest in the sex with the greater variance in reproductive success, usually sons. In contrast, because daughters in many polygynous mammals stay with their mother and compete with her for food, Local Resource Competition theory (e.g. Clark, 1978; Silk, 1983) predicts that the mothers with the greatest reproductive resources should invest in daughters. We investigated the strategy of sex allocation of a captive, outdoor population of 139 mouflon mothers, Ovis musimon, kept in a game state. A complex picture emerged in which, despite weight and body condition being correlated with age in female mouflons, mothers lambed more daughters with increasing age but also, within a given age, gave birth to more sons with increasing weight. Results may be useful in game management aimed at increasing the recruitment or quality of males in managed populations.
\end{abstract}

Key words: Parental investment, reproduction, sex ratio variation, birth sex ratios, mouflon, Ovis musimon, Local Resource Competition strategy, Trivers-Willard strategy, age, weight, Spain

There is clear evidence of biases in offspring sex ratio in mammals (Clutton-Brock and Iason, 1986). One of the earliest and most important theories to account for such biases is that proposed by Trivers and Willard (1973: the 'TriversWillard model' or TWM). They suggested that in polygynous species, a son in good condition at the end of maternal investment should produce more offspring than a daughter in similar condition, whereas the daughter is expected to produce more offspring if both are in poor condition. Therefore, providing that (a) female investment does influence offspring quality, (b) gains from extra parental invest-

*Corresponding author; E-mail: landete@cita-ab.uclm.es; Fax: +34 967599233 
ment persist into adulthood, and (c) similar differences in phenotypic quality have an effect on male reproductive success greater than on that of females, high-quality mothers (i.e. those with greater reproductive resources) should invest more in sons than in daughters (Trivers and Willard, 1973). Natural selection would, therefore, favour a maternal ability to adjust the sex ratio of offspring depending upon the ability of the mother to invest. Such is the case in red deer, where high-ranking females show a more male-biased sex ratio than subordinate females because their sons benefit more than daughters from extra parental investment in terms of adult reproductive success (Clutton-Brock et al., 1984).

In ungulate species where TWM assumptions are met, mothers show a bias in investment towards males either via birth sex ratios, or amount of maternal care (reviewed by Hewison and Gaillard, 1999). One of the predicted consequences of the TWM in these cases is that mothers should incur a greater cost in producing a son than a daughter, and that the effects of such costs should be greater for low-quality than for high-quality mothers. Thus, Gomendio et al. (1990) found that subordinate mothers paid a greater cost in terms of survival and subsequent reproductive success when producing the sex benefiting most from parental investment than the sex benefiting less, whereas no such difference was found in dominant mothers. In addition, Arnbom et al. (1994) found that offspring sex ratio increased with maternal weight above a threshold, below which smaller females had not enough reserves to produce a son.

Clark (1978) and Silk (1983) have argued that when resources are limited locally, a female's fitness can be influenced by her success in obtaining access to these resources and by the competitive success of her offspring (the 'local resource competition' model or LRC). Therefore, because daughters in many polygynous mammals stay with their mother and compete with her for food, only high-quality females are likely to have daughters. Silk (1983) suggested that the greater harassment of dominant mothers towards the daughters of subordinate mothers rather than towards their sons, forced such mothers to bias their offspring sex ratio at birth towards males. Thus, it is the cost of having daughters rather than sons that drives maternal adjustment of offspring sex ratios. Highquality mothers should have a female biased offspring sex ratio and low-quality mothers a male biased ratio in direct contrast to the predictions of the TWM.

Other workers have argued that high-quality mothers should produce more daughters than sons. Verme (1983) and DeGayner and Jordan (1987) proposed that high-ranking deer females should invest in daughters because they are able to control good breeding sites that can pass to their daughters, thereby influencing their reproductive success, but not to their sons as the males disperse from the natal area (the 'advantaged daughter hypothesis'; reviewed in HiraiwaHasegawa, 1993). It has also been suggested that, despite males may have a greater reproductive success, the influence of maternal investment should be measured in terms of reproductive value and not reproductive success (Leimar, 
1996). If quality is maternally transmitted so that reproductive value is higher for daughters, high-quality mothers should invest more in daughters. This has been termed the 'advantaged matriline hypothesis' (Hewison and Gaillard, 1999) and is considered to be a corollary of the previous hypothesis.

As well as studies focusing on the effects of the above strategies at the individual level, others have reported birth sex biases at the population level (McCullough, 1979; Pederson and Harper, 1984; Hoefs and Nowlan, 1994; Kruuk et al., 1999; Post et al., 1999).

In addition to theories predicting opposite biases in sex ratios, Williams (1979) postulated that polytocous species (more than one offspring per litter) should invest their reproductive resources both in a progressive bias towards a particular sex and in larger litters. Thus females bearing similar litter sizes will have more offspring of the most expensive sex the greater their reproductive resources, but will attempt to have a larger litter size of the least expensive sex if they can (therefore if, for example, males are more expensive, a scales of $1 \mathrm{fe}-$ male -1 male -2 females - male and female -2 females would correlate with increasing body condition).

Evidence from ungulate studies provide support for both the TWM and LRC positions (e.g. Verme, 1969, 1985; Ozoga and Verme, 1986; DeGayner and Jordan, 1987; Burke and Birch, 1995; Bérubé et al., 1996; Cassinello and Gomendio, 1996; Kojola, 1997; Kruuk et al., 1999; Post et al., 1999). In primates, it appears that Local Resource Competition is more widespread than Trivers-Willard (reviewed in Hiraiwa-Hasegawa, 1993). Van Schaik and Hrdy (1991) have proposed that the strength of local competition within a population might force individuals to shift from TWM to LRC strategies.

In this study, we investigated the offspring sex bias of mouflons kept in large game estates with native vegetation and other outdoor conditions that may resemble at least specific ecological scenarios of a free-ranging population. Mouflons show a spacing pattern similar to most other polygynous ungulates: daughters stay with their mothers in females groups (Bon et al., 1992), thus competing with her for food, whereas males leave when they are 1-2 years old (Pfeffer, 1967). The species is sexually dimorphic (males 40-45 kg, females 25$30 \mathrm{~kg}$; Tomiczek and Türcke, 1995; Ballesteros, 1998) and there is indirect evidence that lambs of different sexes require different amounts of maternal resources (weight at birth: males $3.5 \mathrm{~kg}$, López et al., 1998; females $2.6 \mathrm{~kg}$, Santiago Moreno et al., 1995, and a higher frequency and duration of suckling bouts for male than for female lambs, Obregón et al., 1988). The mouflon is, therefore, an interesting species because there are aspects of its life history that fit the conditions of both the TWM and LRC. Also, because the mouflon is a commercial game species, it is relatively easy to obtain access to records of variables such as age, weight and body condition. 


\begin{abstract}
Methods
The study was carried out in 1996, in the estate of a game management company sited in Ciudad Real (Centre of Spain), at $38^{\circ} 40^{\prime} \mathrm{N}, 4^{\circ} 10^{\prime} \mathrm{W}$ and $700 \mathrm{~m}$ of altitude where individuals were kept near free-ranging conditions in a 50 ha area. Handling of the animals was kept to the minimum required to maintain population health and commercial profitability. Supplementary food was only provided during harsh conditions when naturally available food was lacking. The vegetation on the estate consisted of typical Mediterranean forest containing mainly evergreen oaks, Quercus rotundifolia, Kermes oak, Quercus coccifera, Aleppo pine, Pinus halepensis, and shrubs such as thyme, Thymus sp.

The subjects of the study were 139 female mouflons: mean age $=3.90 \pm$ 0.18 years (range from 1 to 7 years), mean age of females successfully gestating lambs $=4.36 \pm 0.21$ years $(\mathrm{n}=90$, range 1 to 7 years $)$. Age of females were know from pedigree. Near the end of gestation, females were transferred to a set of 5 ha parks, where they remained until a few days after lambing so that perinatal lamb deaths were reduced and parturition problems solved. In order to reduce the lambing period, the company followed a protocol for synchronisation of the oestrus of the females by means of FGA, a progesterone-like synthetic hormone. We had no way of testing whether oestrus synchronisation influenced the sex ratio, however, we can find nothing in the literature to suggest such an effect. As Table 1 shows, litter size in this species usually varies between 1 and 3 lambs, although most females gave birth to single or twin lambs.

At around the time of conception female mouflons were weighed, and their body condition assessed by an experienced veterinarian using the method developed for sheep by Russel (1984; scoring from 1 to 5 with increasing body condition). By daily searching the lambing parks, we identified the sex of the lambs shortly after birth (by visual examination or using minimal handling). Unfortunately, as we were not allowed to manipulate them or transport them to the balances in the handling premises, we could not determine their weight.

Relationships between continuous variables such as fecundity (number of lambs born including 0 values), age, weight, etc. were assessed with parametric correlations using 2-tail tests. Because the sample size of primiparous females was very small $(\mathrm{n}=8)$, non-parametric ANOVAs (Meddis, 1984) were used to assess differences in weight, age and body condition between primiparous and multiparous females. Chi-square tests were used to assess differences in the sex ratio of primiparous and multiparous females.

A multiple logistic regression model (Netter et al., 1996) was used to test for the effects of litter size and the age, weight, and body condition on the proportion of males in the litters, thus permitting the significance of each variable to be assessed after allowing for the effects of other correlated variables. A backwards stepwise procedure was used to select a final model, basing significance
\end{abstract}


tests on the change in deviance on removing terms to the model, which is approximately distributed as a chi-square with the appropriate degrees of freedom. There was evidence that the data were more variable than would be expected from a binomial distribution (residual deviance of best-fitting model 107.22 with 85 d.f., $P=0.052$ ), and so William's method (Collett, 1991) was used to correct for overdispersion, in order to prevent exaggeration of significance levels. The final model was checked for both interactions between, and non-linearity within, any of the variables.

\section{Results}

Mouflon mothers increased their reproductive resources (energetic reserves) with age, as both weight and body condition correlated with it (correlation between weight and age, $\mathrm{r}=0.621, \mathrm{p}<0.001$; body condition and age, $\mathrm{r}=$ $0.551, \mathrm{p}<0.001$; weight and body condition, $\mathrm{r}=0.568, \mathrm{p}<0.001 ; \mathrm{n}=139$ ). Weight, body condition, and age correlated with fecundity (correlation between fecundity and age, $\mathrm{r}=0.281, \mathrm{p}<0.01$; fecundity and weight, $\mathrm{r}=0.399, \mathrm{p}<$ 0.001 ; fecundity and body condition, $\mathrm{r}=0.292, \mathrm{p}<0.001, \mathrm{n}=139$; Table 1 ).

The stepwise logistic regression model of sex ratio was statistically significant (deviance $=26.83$, d.f. $=4, p<0.001$ ) and showed that sex ratio was affected by litter size, age and weight of the mother at mating, but not by body condition (Table 2). The effect of weight increased the likelihood of having a male, whereas that of age and litter size had the opposite effect (Table 2 and Figs 1 and 2). The effect of age was not completely linear and adding a quadratic term significantly improved the fit of the model. The fitted quadratic curve indicated that the proportion of male lambs, after allowing for the other variables in the model, was approximately constant up to about five years, but then declined rapidly. There were no significant interaction terms: in particular the interaction between age and weight was non-significant.

Despite the small sample size of primiparous females $(n=8)$, the primiparous females that lambed successfully weighed less at mating than multiparous ones (primiparous, $27.2 \pm 0.4 \mathrm{~kg}, \mathrm{n}=8$, multiparous, $30.6 \pm 0.38 \mathrm{~kg}, \mathrm{n}=82$, nonparametric ANOVA, $\mathrm{Z}=3.612, \mathrm{p}<0.001$ ) and scored lower in body condition $(\mathrm{Z}=2.622, \mathrm{p}<0.01)$. However, no difference in sex ratio was found either after adjustment for the other factors in the model (Table 2) or without any adjustment $\left(\chi^{2}=0.39,1\right.$ d.f. ns; sex ratio of primiparous females $=0.66$, number of lambs $=$ 9 , sex ratio of multiparous females $=0.50$, number of lambs $=111$ ). 


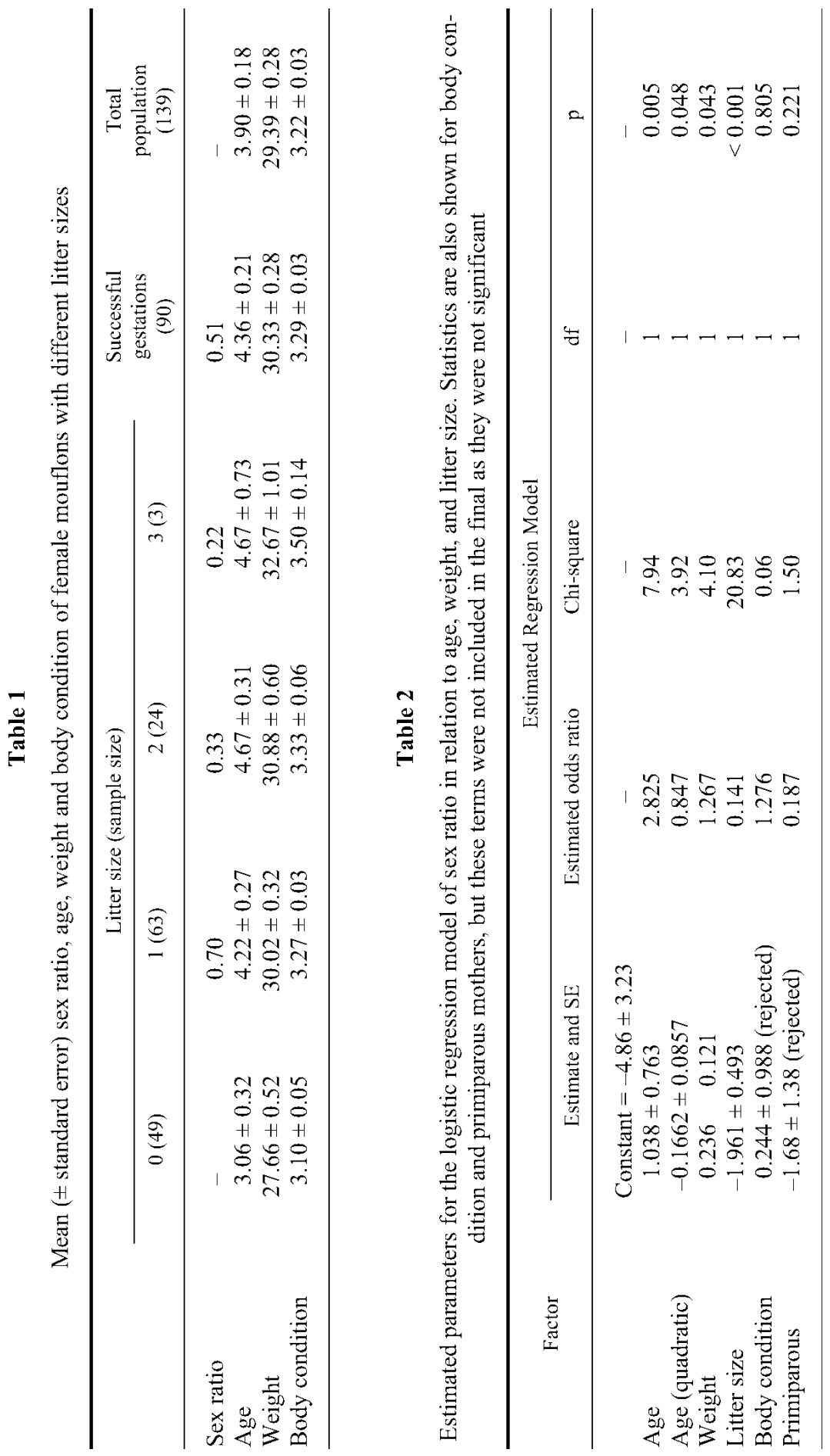



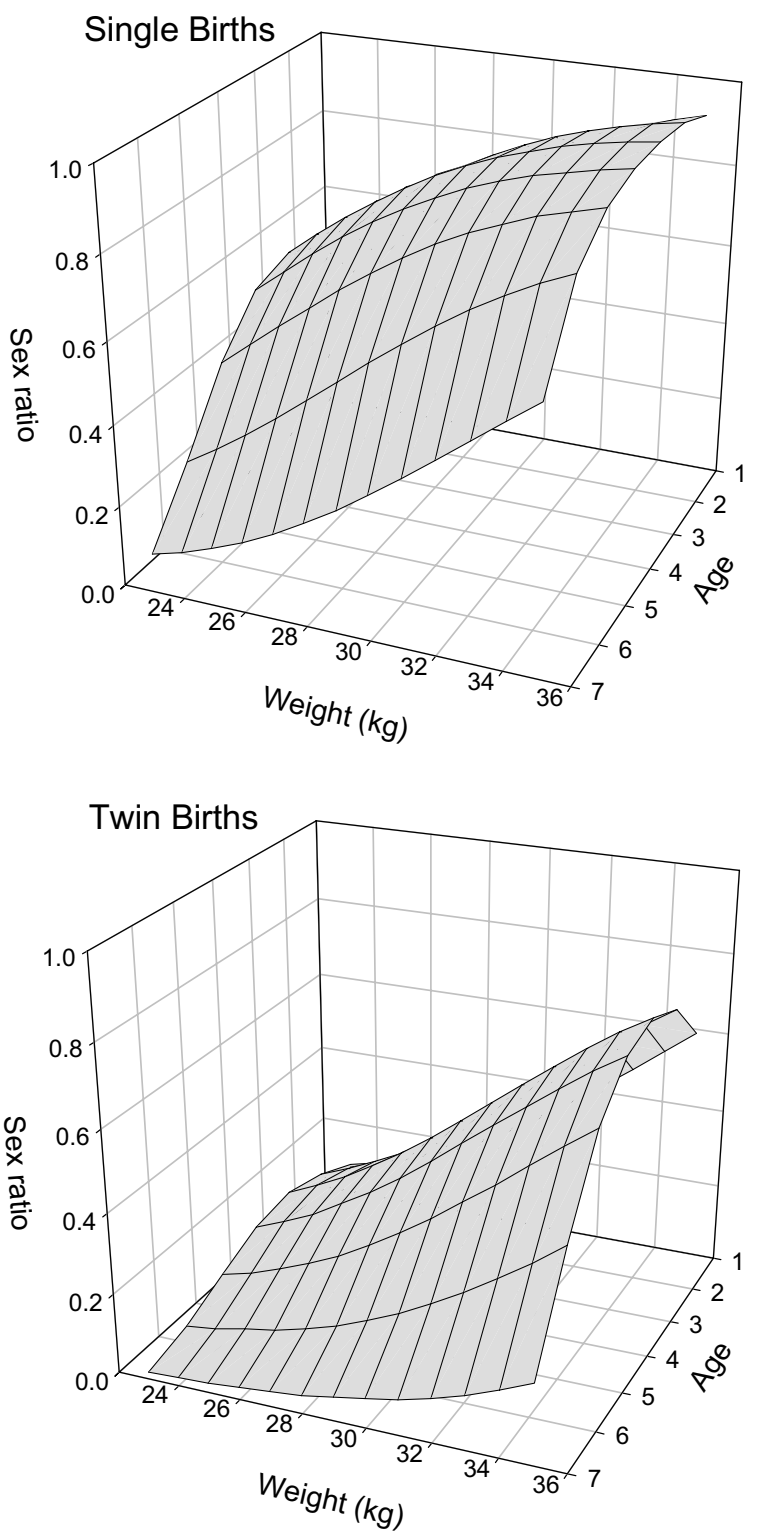

Fig. 1. Proportion of males in relation to maternal age and weight at mating for single $(\mathrm{n}=63)$ and twin $(n=24)$ births (N.B. there were only three triple births). The surface corresponds to the fitted logistic curve $\mathrm{P}=\exp ($ eta) / $(1+\exp ($ eta) $)$, where $\mathrm{P}$ is the proportion of males in a litter and eta equals, respectively, for litters of size 1 and 2 , eta $(1)=-6.50544-0.395763$ age +0.216859 weight +2.58799 ; eta $(2)=-6.50544-0.395763$ age +0.216859 weight +0.929001 . Although for clarity, the values have been computed for the full range of weight and age shown by successful breeding females, note that some values are very unlikely (e.g. the heaviest females within younger classes and vice versa) 

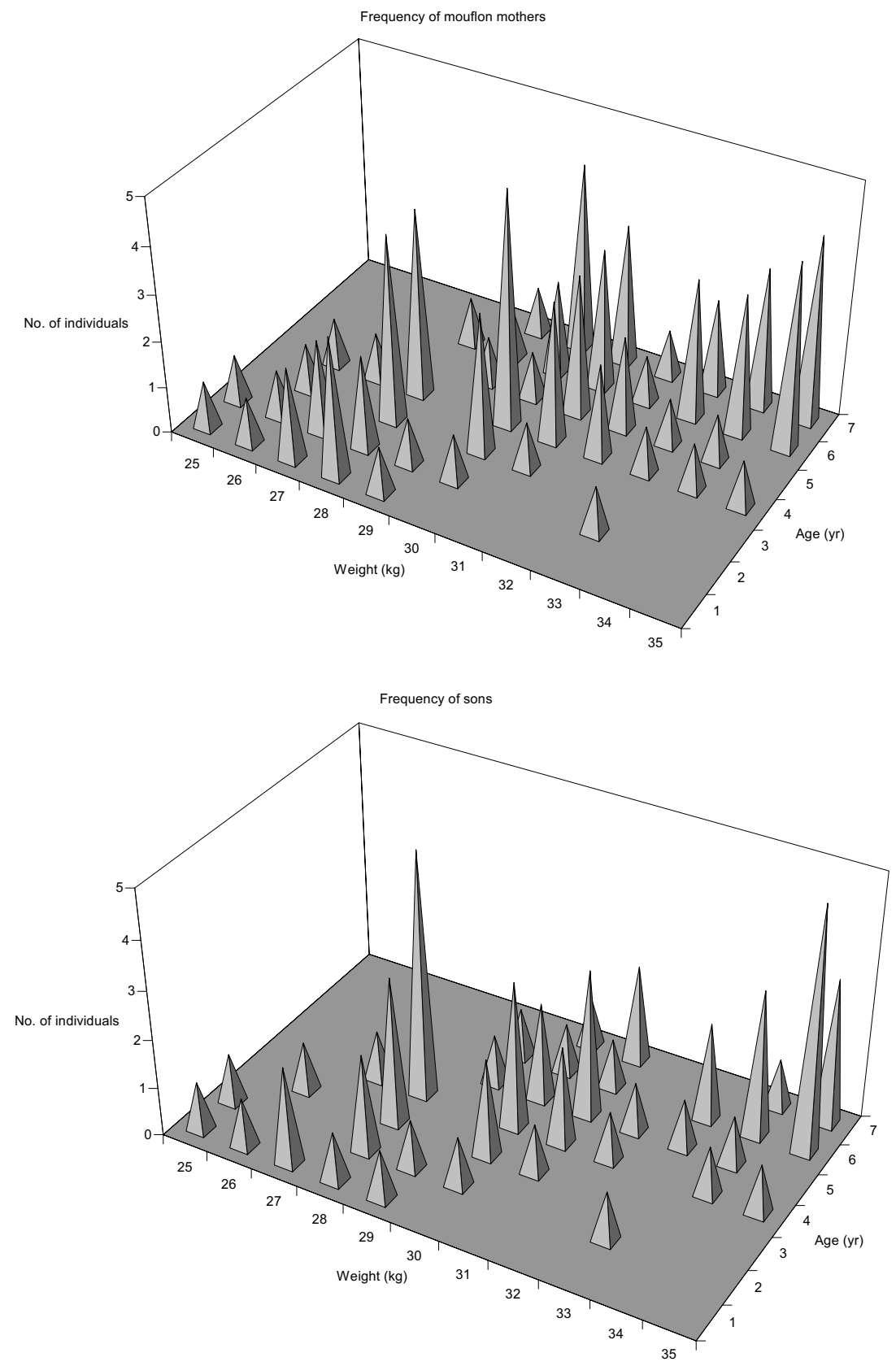


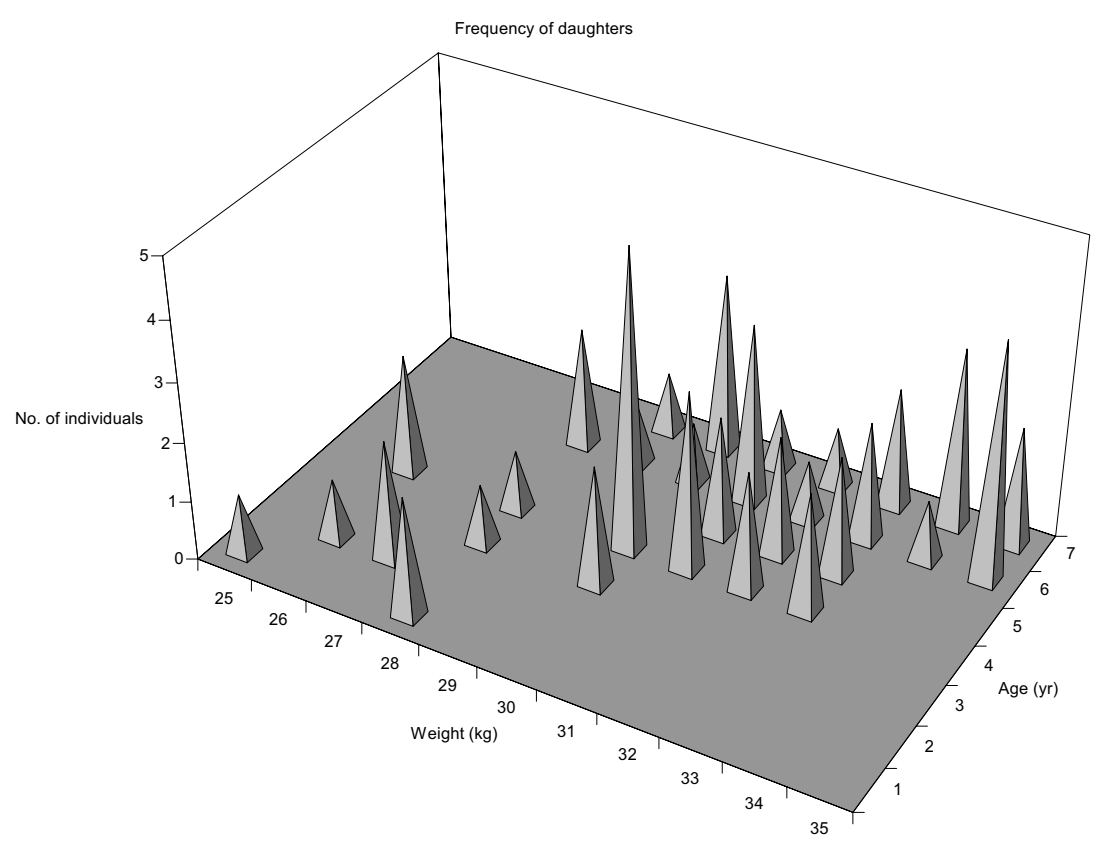

Fig. 2. Number of mouflon mothers and their sons and daughters born from individuals in every age and weight class. Both age and weight have been rounded to their nearest integer

\section{Discussion}

Our data on the sex ratio of mouflon offspring reveal a complex picture with older mothers showing a bias towards daughters but also, within a given age group, heavier mothers revealing a bias towards sons. This may reflect differences between the sexes in their short and long-term costs to the mother rather than on a strategy aimed to optimise the lifetime reproductive success of offspring, as predicted by TWM and LRC/advantaged daughter hypothesis.

Proximate costs of producing a son seem to be greater than those of producing a daughter in many sexually dimorphic ungulates. Clutton-Brock et al. (1981) found that female red deer transfer a greater proportion of their body reserves to sons than to daughters and Gomendio et al. (1990) reported that subsequent survival of subordinate red deer mothers is depressed more by having a son than by having a daughter. In Rocky Mountain bighorn sheep, closely related to the European mouflon, ewes that weaned a son were less likely to reproduce successfully the following year, lambs were more likely to survive their first year if born after a daughter than if born after a son, and ewes were unlikely to have sons on consecutive years (Bérubé et al., 1996). In addition, male lambs suckled their mothers for longer and more frequently than female in Spanish populations 
of mouflons (Obregón et al., 1988), a behaviour also found in red deer and which is believed to indicate a greater transfer of nutrients to sons (Clutton-Brock et al., 1982). The effect of mother weight on offspring sex ratio at birth (after correcting for age and litter size) suggests that mouflons may be showing a similar pattern to that found in deer and other ungulates. Thus, lighter females would be more likely to have daughters to avoid the higher raising costs (e.g. greater birth weight and suckling demands) associated with sons. This might also explain the negative correlation between litter size and a male-biased sex ratio in the offspring: i.e. the larger the litter size, the less is available for the greater requirements of sons. Although the bias shown may be coupled with a greater investment in males with increasing weight, which in turn is likely to increase the lifetime reproductive success of male mouflons, this is not the whole story as otherwise the larger females in absolute terms (also the older) would be the most likely to have sons.

Despite the correlation between weight and age, mouflons also showed an increasing birth sex bias towards females the older they were, after correction for weight and litter size. Although mouflon daughters appear to be less expensive to rear than sons, they stay with their mothers and hence constitute a greater longterm cost. Mouflon mothers may give birth to more daughters as they age because their expected reproductive success (reproductive value) also decreases with age and hence their fewer remaining breeding opportunities means reduced impact of their philopatric daughters.

This effect on sex ratio at birth may also be a strategy to influence the lifetime reproductive success of daughters by transmitting dominance or some other quality trait, or allowing them to inherit breeding sites. Although our results do not allow to discriminate between these hypothesis, a strategy to optimise LRS based on inheritance of breeding sites or quality seems less likely than a response to long-term costs because, for animals of a similar age, heavier females are more likely to have such attributes to pass to their daughters and yet these females bear sons. In addition, although the age effect observed is compatible with LRC, our data do not seem to support the harassment mechanism proposed for this theory. Silk (1983) argued that subordinate females would not be able to withstand the harassment of their daughters by dominant females, and hence only the dominant (usually the heaviest) females could afford to have daughters. In our case, the heaviest mouflon mothers for any given age are more likely to give birth to sons.

\section{Acknowledgements}

The authors wish to thank Mr. Luis Vioque for his help during handling of the animals and collection of data for this publication, and F. R. López-Serrano for help during the analysis of the data. 


\section{References}

Arnbom, T., Fedak, M. A. and Rothery, P. (1994): Offspring sex ratio in relation to female size in southern elephant seals, Mirounga leonina. Behav. Ecol. Sociobiol. 35, 373-378.

Ballesteros, F. (1998): Las especies de caza en España, biología, ecología y conservación. Estudio y Gestión del Medio, Colección Técnica, Oviedo, Spain.

Bérubé, C. H., Festa-Bianchet, M. and Jorgenson, J. Y. (1996): Reproductive costs of sons and daughters in Rocky Mountain bighorn sheep. Behav. Ecol. 7, 60-68.

Bon, R., Gonzalez, G., Estevez, I. and Recarte, J. M. (1992): Comparison of social patterns during the rut within three European populations of Corsican mouflons (Ovis gmelini). Etología 2, 9-20.

Burke, R. L. and Birch, J. M. (1995): White-tailed deer vary offspring sex-ratio according to maternal condition and age. Ecol. Res. 10, 351-357.

Cassinello, J. and Gomendio, M. (1996): Adaptative variation in litter size and sex ratio at birth in a sexually dimorphic ungulate. Proc. Royal Soc. London B 263, 1461-1466.

Clark, A. B. (1978): Sex ratio and local resource competition in a prosimian primate. Science 201, $163-165$.

Clutton-Brock, T. H. and Iason, G. R. (1986): Sex ratio variation in mammals. Quart. Rev. Biol. 61, 339-374.

Clutton-Brock, T. H., Albon, S. D. and Guinness, F. E. (1981): Parental investment in male and female offspring in polygynous mammals. Nature 289, 487-489.

Clutton-Brock, T. H., Albon, S. D. and Guinness, F. E. (1984): Maternal dominance, breeding success and birth sex ratios in red deer. Nature 308, 358-360.

Clutton-Brock, T. H., Guinness, F. E. and Albon S. D. (1982): Red deer: Behavior and ecology of two sexes. University of Chicago Press, Chicago, USA.

Collett, D. (1991): Modelling Binary Data. Chapman and Hall, London, UK.

DeGayner, E. J. and Jordan, P. A. (1987): Skewed fetal sex ratios in white-tailed deer: evidence and evolutionary speculations. In: Wemmer, C. M. (ed) Biology and Management of the Cervidae. Smithsonian Institution Press, Washington, USA.

Gomendio, M., Clutton-Brock, T. H., Albon, S. D., Guinness, F. E. and Simpson, M. J. (1990): Mammalian sex ratios and variation in costs of rearing sons and daughters. Nature 343, 261-263.

Hewison, A. J. M. and Gaillard, J. M. (1999): Successful sons or advantaged daughters? The Trivers-Willard model and sex-biased maternal investment in ungulates. Trends in Ecology and Evolution 14, 229-234.

Hiraiwa-Hasegawa, M. (1993): Skewed birth sex ratios in primates: should high-ranking mothers have daughters or sons? Trends in Ecology and Evolution 8, 395-400.

Hoefs, M. and Nowlan, U. (1994): Distorted sex ratios in young ungulates: the role of nutrition. J. Mammalogy 75, 631-636.

Kojola, I. (1997): Social status and physical condition of mother and sex ratio offspring in cervids. Appl. Anim. Behav. Sci. 51, 267-274.

Kruuk, L. E. B., Clutton-Brock, T. H., Albon, S. D., Pemberton, J. M. and Guinness, F. E. (1999): Population density affects sex ratio variation in red deer. Nature 399, 459-461.

Leimar, O. (1996): Life-history analysis of the Trivers and Willard sex-ratio problem. Behav. Ecol. 7, 316-325.

López, A., Garcia, A., López, J., Garde, J. and Gallego, L. (1998): Cría de neonatos de muflón ( $O$. a. musimon) mediante lactancia artificial. Consideraciones sobre el riesgo de infecciones y parasitosis. Galemys 10, 3-12.

Meddis, R. (1984): Statistics Using Ranks. Basil Blackwell, Oxford, UK.

McCullough, D. R. (1979): The George Reserve Deer Herd: population ecology of a K-selected species. University of Michigan Press, Ann Arbor, USA. 
Netter, J., Kutner, M. H., Nachtsheim, C. J. and Wasserman, W. (1996): Applied Linear Statistical Models. Fourth Edition. Irwin, Chicago, USA.

Obregón, F., Arias de Reyna, L., Recuerda, P. and Castro, F. (1988): Inversión maternal según el sexo de la cría en muflón (Ovis musimon). In: II Congreso Nacional de Etología. Estación Biológica de Doñana, Sevilla, Spain.

Ozoga, J. J. and Verme, L. J. (1986): Initial and subsequent maternal success of white-tailed deer. Journal of Wildlife Management 50, 22-124.

Pederson, J. C. and Harper, K. T. (1984): Does summer range quality influence sex ratios among mule deer fawns in Utah? Journal of Range Management 37, 64-66.

Pfeffer, P. (1967): Le mouflon de corse (Ovis ammon musimon Schreber, 1782); position systematique, ecologie et ethologie comparees. Mammalia 31 supp., 1-262.

Post, E., Forchhammer, M. C., Stenseth, N. C. and Langvatn, R. (1999): Extrinsic modification of vertebrate sex ratios by climatic variation. The American Naturalist 154, 194-204.

Russel, A. (1984): Body condition scoring of sheep. Farm Practice 6, 91-93.

Santiago Moreno, J., González de Bulnes, A., García López, M., Gómez Brunet, A. and López Sebastián, A. (1995): Estudio comparativo del índice de crecimiento y características cualitativas de la leche en el muflón (Ovis ammon musimon) y la oveja (Ovis aries). Producción Ovina y Caprina 20, 473-477.

Silk, J. B. (1983): Local resource competition and facultative adjustment of sex ratios in relation to competitive abilities. The American Naturalist 121, 56-66.

Trivers, R. L and Willard, D. E. (1973): Natural selection of parental ability to vary the sex ratio. Science 179, 90-92.

Tomiczek, H. and Türcke, F. (1995): Das Muffelwild. Verlag Paul Parey, Hamburg, Germany.

Van Schaik, C. P. and Hrdy, S. B. (1991): Intensity of local resource competition shapes the relationship between maternal rank and sex ratios at birth in cercopithecine primates. The American Naturalist 138, 1555-1562.

Verme, L. J. (1969): Reproductive patterns of white-tailed deer related to nutritional plane. Journal of Wildlife Management 33, 881-887.

Verme, L. J. (1983): Sex ratio variation in Odoicoleus: a critical review. Journal of Wildlife Management 47, 573-582.

Verme, L. J. (1985): Progeny sex ratio relationships in deer: theoretical vs. observed. Journal of Wildlife Management 49, 134-136.

Williams, G. C. (1979): The question of adaptative sex ratio in outcrossed vertebrates. Proc. Royal Soc. London B 205, 567-580. 